UDK: 75.071(497.6 Srebrenica)

Izvorni znanstveni članak

Primljen 18. IX. 2019.

Amila HandžIĆ Ferović

Univerzitet u Sarajevu, Akademija likovnih umjetnosti Sarajevo

amilahandzic@gmail.com

\title{
KULTURNA DIMENZIJA SJEĆANJA NA GENOCID U SREBRENICI
}

\section{Sažetak}

Osnovna je ideja ovoga rada tumačenje genocida u Srebrenici kroz pojam i značenje „kulturne traume“. Istraživanje je zasnovano na analizi i propitivanju vizualnih i značenjskih dimenzija rada bosanskohercegovačke umjetnice Šejle Kamerić u radu Bosnian Girl te jumbo plakata 1945-19952005 fotografa Tarika Samaraha. Radovi nastali u poslijeratnome razdoblju prepoznaju se kao ključni kulturni mehanizmi interpretiranja i razumijevanja srebreničkih traumatičnih zbivanja. Iskazi izmijenjena i fragmentirana kolektiviteta ogledaju se u okvirima značenjski oblikovane prošlosti različitim vizualnim sredstvima i njihovim međusobnim odnosima. Snažni simbolički potencijal spomenutih radova autorica promatra kao prostor arhiviranja znanja i kulturne dimenzije sjećanja na genocid $u$ Srebrenici te integriranja povijesnoga sadržaja u okvire suvremenoga i budućega bosanskohercegovačkog društvenog konteksta. Radovi umjetnice Kamerić i fotografa Samaraha, kao narativi kulturnoga pamćenja, problematiziraju utjecaj prošlosti na procese re/konstrukcije kolektivnoga identiteta.

Ključne riječi: genocid; kulturna trauma; kulturno pamćenje; narativni diskurs; kolektivni identitet 


\section{Uvod}

Ratnu 1995. godinu bosanskohercegovačka povijest ispisuje kao godinu u kojoj se dogodio najgori pokolj u Europi nakon Drugoga svjetskog rata. Genocid u Srebrenici, gradu u istočnoj Bosni, izvršen je između 11. i 22. srpnja, a izravnim počiniteljima, kako je to potvrđeno presudom $\mathrm{Me}-$ đunarodnoga suda za ratne zločine na području bivše Jugoslavije u Haagu, proglašeni su vojnici Vojske Republike Srpske pod predvodništvom generala Ratka Mladića. Osvojiti regiju Srebrenice bio je dio strateškoga plana kreiranja i integriranja srpskih etnički čistih teritorija. Njezino pripajanje Republici Srpskoj rezultiralo bi teritorijalnim ujedinjenjem s Republikom Srbijom i okolnim područjima nastanjenim srpskim stanovništvom: „S tako postavljenim ciljem, tokom 1992. i početkom 1993. godine, snage bosanskih Srba pokrenule su kampanju etničkog čišćenja nesrpskog stanovništva u području Podrinja (dolina rijeke Drine) u gradovima Višegrad, Bratunac, Zvornik, Srebrenica i okolnim selima“ (Nuhanović, 2008: 17). Vijeće sigurnosti un-a 1993. usvojilo je Rezoluciju 819 stavljajući Srebrenicu pod zaštitu međunarodnih mirovnih snaga. Od toga trenutka zaštićena srebrenička zona pruža utočište za 40 ooo muslimanskih izbjeglica, raseljenih i prognanih iz okolnih okupiranih gradova i sela. Unatoč Rezoluciji Vojska Republike Srpske nije odustala od svoga nauma. Više od 8 ooo nenaoružanih bosanskih muslimana monstruozno i masovno je pogubljeno u okviru vojne operacije kodnoga imena Krivaja 95. „Pomoć međunarodne zajednice, prije svega Nizozemskog bataljona koji je dodijeljen enklavi Srebrenica, kao i pomoć snaga NATO-a izostaje. Odvajanje starijih dječaka i muškaraca odvijalo se uz prisustvo pripadnika UNPROFOR-a, zvaničnika UN-a i drugih međunarodnih organizacija, čime je 'zaštićena zona Ujedinjenih nacija' prepuštena na milost i nemilost napadaču" (usp. Nuhanović, 2008: 38).

U poslijeratnim godinama započeta je istraga o zločinima počinjenima na srebreničkome tlu, a zatim i pretraživanje okolnih terena, iskopavanje posmrtnih ostataka i proces identificiranja žrtava. Godine 2003. službeno je otvoren Memorijalni centar Srebrenica - Potočari, spomen-obilježje i mezarje za žrtve genocida iz 1995. godine, kada je 
ukopano prvih 600 identificiranih žrtava. Uzastopnim ukopima 11. srpnja svake godine održava se neprekidnost sjećanja na srebrenički masakr. Srebrenička tragedija nije okončana ni dvadeset i više godina poslije. Intenzivno se traga za tijelima žrtava te se neprekidno sprovode sudski procesi u okvirima lokalnih i regionalnih sudova jer je Međunarodni sud za ratne zločine na području bivše Jugoslavije (ICTY) 2017. službeno prestao s radom.

S ciljem promatranja, razumijevanja, artikuliranja, prevazilaženja i pronalaska odgovora na srebreničku traumu nastali su radovi Šejle Kamerić i Tarika Samaraha. Radove kreirane u različitim vremenskim okvirima označavaju zajednički plakatni medij, primarno zasnovan na fotografskoj slici, te aktualnost na nacionalnoj, internacionalnoj, društvenoj i umjetničkoj sceni, a u okvirima ovoga rada bit će predstavljeni kao ključni narativni mehanizmi u kulturnoj organizaciji sjećanja na genocid u Srebrenici. Njihova interpretativna i značenjska dimenzija, posredovana vizualnim retoričkim sredstvima, sagledat će se iz pozicije oblikovanja traumatskoga diskursa te aktivna sudjelovanja u procesu restrukturiranja kolektivnoga identiteta. Analiza rada usmjerena je na promatranje genocida u Srebrenici kroz značenje pojma kulturne traume.

\section{Kulturno pamćenje kao proces posredovanja traumatskoga značenja}

Pojam traume u suvremenim studijama i teorijama sjećanja svojim definiranjem nadilazi iskustveni aspekt traumatskoga stavljajući u središte promatranja posljedice traumatične prošlosti i njihov utjecaj na kolektivni identitet. Time diskurs traume i traumatičnoga iskustva širi svoj opseg prema propitivanju načina putem kojih trauma sudjeluje u procesu re/konstruiranja sjećanja, a u svrhu sagledavanja posljedica traumatičnoga iskustva na pojedinca i kolektiv. S ciljem definiranja pojma kulturne traume, traumatično djelovanje preispituje se iz pozicije prirodne datosti traumatičnoga događaja, ali i društvene uvjetovanosti i konstrukcije. 
Ron Eyerman u svojoj knjizi Cultural Trauma - Slavery and the Formation of African American Identity pravi razliku između psihološke ili fizičke i kulturne traume. Prvu „označava uzročno posljedično vid ozljeđivanja i iskušavanja velike emocionalne boli pojedinca, dok se kulturna trauma pak referira na dramatičan gubitak identiteta i značenja, a koji utječe na skupinu ljudi koji su postigli određeni stupanj kohezije" (2001: 2). Kulturnu ili nacionalnu traumu (razlika je minimalna na teorijskoj razini) određuje „uzrok“, tj. događaj čije se traumatično značenje uspostavlja, interpretira i prihvaća vremenom, posredovanjem i modalitetima predstavljanja (usp. Eyerman, 2001: 3). Kulturnu traumu određuju različiti prostorni i vremenski, sadašnji i budući društveno-kulturni procesi, sredstva posredovanja i rekonstrukcije traume, čime traumatsko iskustvo prelazi put od traumatičnoga događaja do traumatičnoga utjecaja. Djelovanje traumatičnoga događaja ne počiva isključivo u izravnome iskustvu, već njegovo značenje i uspostavljanje uvjetuje društveno-kulturni kontekst te proces komuniciranja, simboličkoga predstavljanja i definiranja. Nastojeći naglasiti razliku između izravna i društveno konstruirana traumatskog iskustva, Elżbieta Hałas umjesto pojma „kulturna trauma“ predlaže pojam „kulturno sjećanje na traumu“ (2010: 316). „Analiza traume kao kulturnog fenomena se može zasnivati na konceptu kulturne memorije i njenim bitnim dimenzijama, kao što su: komunikacija, refleksivnost znanja o prošlosti, (...), i, posljednje, ali ne manje važno, orijentacija prema budućnosti." (2010: 315).

Kulturno pamćenje (vidi Assmann - Czaplicka, 1995: 125 - 133), kolokvijalno interpretirano kao radno ili značenjsko (vidi Brockmeier, 2002: 5 - 14), ne može se poistovijetiti s pojmovima društvenoga, kolektivnoga i povijesnoga pamćenja (vidi Halbwachs, 1980) koji mu se vrlo često pripisuju. Na koji način pojedinac i kolektiv zasnivaju sjećanje na određeni događaj? Francuski filozof i sociolog Maurice Halbwachs, objašnjavajući koncept kolektivnoga pamćenja, odbacuje mogućnost postojanja individualnoga pamćenja odvojena od društvenoga. Individualno pamćenje, prema ovomu autoru, sadržano je u elementima interaktivnoga čina s drugima. Pojedinci mogu stjecati, ograničavati i prizivati svoja sjećanja jedino kroz članstvo ili pripadnost kolektivu (usp. Halbwachs, 
1980: 51). Stoga društvena skupina, bila zemljopisno, ideološki, politički, srodstveno, religijski, klasno ili generacijski utemeljena, osigurava pojedincima mentalni i materijalni okvir unutar kojega su njihova sjećanja lokalizirana (vidi Halbwachs, 1980). „Tako zamišljena, kolektivna memorija ne znači 'zajedničko sjećanje' ili čak tumačenja sa kojima se većina ljudi slaže; to znači da pojedinci oblikuju uvjerenja o prošlosti kroz interakciju s drugima" (Schwartz - Fukuoka - Takita-Ishii, 2005: 254). Kolektivno se sjećanje, dakle, zasniva na oblikovanju sadržaja i značenja povijesnoga konteksta, čije je tumačenje određeno trenutačnim potrebama i interesima kolektiva. Time sjećanje ne biva koherentno, već opstaje na razini procesa ili, drugim riječima, metanarativnoga diskursa. Postavlja se pitanje: „Na temelju čega opstaje stalno sjećanje na razini kolektiva, ako izostaje zajednički jezik u interpretaciji određenoga sadržaja iz prošlosti i ako je sjećanje određeno kulturnim i povijesnim kontekstom u kojem se odigrava?" Odgovor na ovo pitanje moguće je pronaći u okviru teorijskih promišljanja i studija pamćenja Jana Assmanna koji u središte kritike stavlja pojam kolektivnoga pamćenja kao nositelja kolektivnoga identiteta, razlažući ga na pojmove komunikativnoga i kulturnoga pamćenja. Za razliku od komunikativnoga pamćenja koje se prakticira u svakodnevnome životu i koje određuje ograničeni vremenski horizont, kulturno pamćenje označeno je distancom od svakodnevnoga (usp. Assmann, 1995: 127 - 129) Kulturno pamćenje određuju fiksne točke ili sudbonosni događaji iz prošlosti čije se sjećanje održava kroz kulturne formacije (tekstovi, obredi, spomenici) i putem institucionalnoga komunikativnog diskursa (usp. Assmann, 1995: 129). Njezin institucionalni karakter, objektiviziranost i pohranjenost unutar simobličkih formi nudi mogućnost prijenosa sjećanja s generacije na generaciju. Sjećanja postaju evocirana i locirana u interaktivnome činu izvanjskim simbolima, poput spomenika, muzeja, knjižnica, arhiva i drugih mnemoničkih mehanizama. Dok kolektivno pamćenje obuhvaća znanje koje dijeli društvo određene povijesne epohe, kulturno pamćenje vrši njegovo arhiviranje i preoblikovanje. Drugim riječima, kulturno pamćenje svoje uporište pronalazi u komunikacijskim aktima koji prenose refleksivno znanje o prošlosti iz perspektive budućnosti. No, još je važnije 
od njezina vremenskog trajanja to što kulturno pamćenje karakterizira „konkretizacija identiteta” (Assmann, 1995: 130). Jan Assmann objašnjava: „Kulturna memorija pohranjuje znanje na osnovu kojeg grupa gradi svijest o svom jedinstvu i naročitosti“ (Assmann, 1995: 130). Dakle, postojanje kolektivnoga identiteta uvjetovano je uspostavom kolektivnoga znanja pohranjena u okvire kulturnoga sjećanja.

Predočenu tumačenju i shvaćanju pojma kulturnoga pamćenja pridružuje se definiranje pojma kolektivnoga pamćenja Anne Lise Tote. U radu pod nazivom Counter-Memories of Terrorism: The Public Inscription of a Dramatic Past autorica u središte svoga promatranja postavlja najprikladnije kulturne oblike i komemorativne društvene prakse kao procese i uporišta koja fiksiraju odnos kolektivnoga znanja i sjećanja. Alatke preko kojih se ostvaruje javni ispis prošlosti, koje su zasnovane na vrsti koda te posjeduju snagu u kreativnome i oblikovnome procesu sadržaja kolektivnoga pamćenja, Ana Lisa Tota naziva „tehnologijama pamćenja“ (2005: 273). Na taj je način kolektivno sjećanje zasnovano u odnosu između forme i sadržaja samoga sjećanja. Stoga je postojanje kulturnih artefakata, koji postaju nositelji značenja i sjećanja, nužno za procese prevazilaženja, sagledavanja, razumijevanja i interpretiranja određenoga povijesnog sadržaja.

\section{Narativne dimenzije i prakse kulturnoga pamćenja}

Prakse kulturnoga pamćenja podrazumijevaju raznolike simboličke i materijalne forme: „One obuhvaćaju ne samokulturne artefaktekoji su namjenski načinjeni u komemorativne svrhe (izložbe, filmovi i spomenici) nego i mehanizme memorije i arhive, kao i arhitekturu i geografske lokacije u kojima je memorija utjelovljena i sjećanje semiotički kodirano" (Brockmeier, 2002: 12). Kulturno pamćenje uvijek je oblikovano i definirano društvenim praksama i drugim kulturnim mehanizmima: „Njeno razumijevanje obuhvata proučavanje'simbola, kodova, artefakata, obreda i mjesta na kojima se memorija utjelovljuje i objektivizira; koherentnosti ili fragmentiranost pripovijesti, rituala, geografija, pa čak i epistemologija na koje se oslanja; i način na koji se njihov autoritet 
mijenja tijekom vremena'“ (usp. Lambeck - Antze, 1996, prema: Brockmeier, 2010: 13). Prošlost se „ne priziva jedino kroz formu sjećanja (...) također se prošlost podsjeća, zamišlja, povezuje sa artefaktima od kojih su neki uređeni i određeni u tu svrhu" (Eyerman, 2001: 9). U tome procesu sadržan je čin rekonstrukcije i reinterpretacije pri čemu se sjećanje mijenja shodno promjeni konteksta i okolnostima u kojima se odvija.

Brockmeier smatra da narativni diskurs ima presudnu ulogu u povezivanju individualnih i društveno-povijesnih dimenzija sjećanja. Da bismo razumjeli ulogu narativne dimenzije kulturnih artefakata u kulturnoj artikulaciji sjećanja te u uspostavljanju temelja povijesnoga kontinuiteta i tradicije određenoga društva, neophodno je proučiti narativne registre kulture, tj. sadržaj, oblike i funkcije narativne prakse (usp. Brockmeier, 2002: 11). Narativne prakse koje oblikuju sjećanje ne postoje kao dani predlošci, već zauzimaju aktivno sudjelovanje u prijenosu znanja: „Proučavati narativni diskurs znači ispitati njegove diskurzivne prakse, kulturne tekstove i kontekste" (Brockmeier - Harré, 2001: 53).

Sredstva i mediji predstavljanja jako su važni jer premošćuju jaz između pojedinca, traumatičnoga događaja i sjećanja na njega (usp. Eyerman, 2001: 12). Njihov je cilj rekonstruirati ili preoblikovati kolektivni identitet kroz kolektivno predstavljanje, s namjerom prevazilaženja i razumijevanja traumatičnoga događaja koji narušava integritet društvene zajednice. U tome procesu izranja potreba za „pripovijedanjem o novim temeljima" (Hale, 1998: 6) te se, stoga, sjećanje utjelovljeno u javnim spomenicima, muzejima ili obljetnicama ne odnosi samo na prošlost nego obuhvaća i mehanizme funkcioniranja sjećanja radi suočavanja sa sadašnjim i budućim društvenim potrebama i uvjetima (usp. David, 2008: 138). U ovome procesu neophodno je skrenuti pažnju na intelektualne skupine koje su posrednici i prevoditelji društvenoga stanja, poput filmskih reditelja, umjetnika, aktivista, fotografa i dr.

Njihov trag ostaje zapisan i u vremenu koje tek dolazi te se tako oblikuje i posreduje sjećanje generacijama koje nisu imale direktno iskustvo s određenim povijesnim trenutkom. Takve alatke i kulturne manifestacije sjećanja prepoznajemo upravo u radovima bosanskohercegovačke umjetnice Šejle Kamerić i fotografa Tarika Samaraha, koji vlastitim 
moralnim i društvenim stavovima prave put u prevazilaženju, sagledavanju, razumijevanju i artikuliranju genocida u Srebrenici. Oni postaju ključni akteri u prijenosu znanja, arhiviranju sjećanja, ali i integriranja povijesnoga sadržaja u okvire budućega bosanskohercegovačkog konteksta i identiteta.

Cilj je ovoga rada kroz likovno-značenjsku analizu promotriti pojedinačne narativne ispise autora te njihovu ulogu u rađanju znaka izmijenjena poslijeratnog identiteta. Kamerić i Samarah bave se posljedicama traumatičnoga čina i podsjećaju nas na osnovna ljudska prava i potrebe. Njihova vizualna narativna dimenzija preispituje ovostoljetne vrijednosti ljudskoga postojanja te novonastale sustave i kontekst društvenoga funkcioniranja. Radove bosanskohercegovačkih autora moguće je svrstati u područje mentalno-tehničko-kulturnih procesa (usp. Dijck, 2007, prema Brockmeier, 2010: 15) koji utječu na druge kulturne prakse zadužene za kreiranje i operiranje sjećanjima.

\section{Bosnian Girl (2003) Šejle Kamerić}

Godine nakon genocida u Srebrenici obilježene su nizom aktivnosti, domaćih i internacionalnih razmjera, s ciljem pronalaska i procesuiranja počinitelja. Na Međunarodnome sudu za ratne zločine na području bivše Jugoslavije u Den Haagu podignute su optužnice za ratne zločine na području Bosne i Hercegovine kao i za počinjene zločine u Srebrenici. Godina 2003. obilježena je ukopom prvih identificiranih žrtava u mjestu Potočari. Iste godine nastaje Bosnian Girl Šejle Kamerić (slika 1.). 


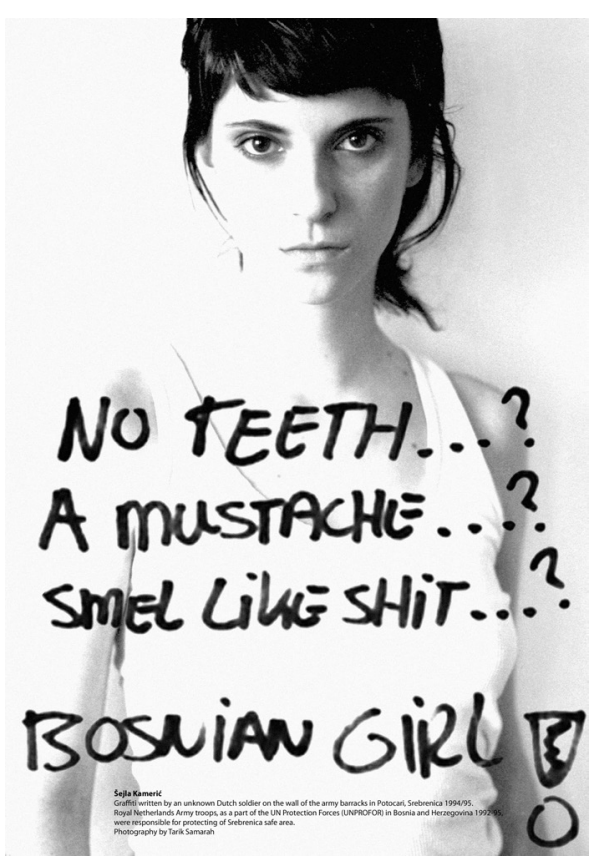

Slika 1.: Šejla Kamerić - Bosnian Girl (2003) (Ljubaznošću umjetnice)

Bosnian Girl, rad umjetnice Kamerić, predstavlja čin iskazivanja vlastitoga stava spram srebreničkoga stradanja. Istinsku vrijednost rada pronalazimo u spontanome kolažiranju i tretiranju likovnih elemenata, jednako kao i u složenosti procesa izgradnje značenjskih odnosa. Crno-bijeloj fotografiji tehnikom kolažiranja pridružen je grafit nizozemskoga vojnika UNPROFOR-a iz tvornice akumulatora u Potočarima. ${ }^{1}$ Intertekstualnim činom autorica preuzima grafit od Tarika Samaraha koji je među prvim fotografima dobio dozvolu za ulazak u tvornicu nakon tragičnih događaja iz 1995. godine. Pored vidljivih tragova stradanja Samarah svojim objektivom bilježi grafite koje su ispisali nizozemski vojnici za vrijeme boravka u Potočarima. Jedan od njih bio je i onaj o bosanskoj djevojci: „No teeth...? A mustache...? Smell like shit...? Bosnian girl...!" Fotografija grafita, shodno definiranju Rolanda Barthesa,

„Tvornica akumulatora u Potočarima je u vrijeme protekcije srebreničke zone bila glavna baza i komanda holandskog bataljona" (Nuhanović, 2005: 144). 
posjeduje jedinstveno referencijalni odnos prema stvarnomu. Slika ispisa postojala je i svjedočila jednomu vremenu i prostoru mnogo prije nego što je zabilježena fotografskim objektivom. Grafit nizozemskoga vojnika ili fotografski referent jest "stvarnost ili istinitost na koju se slika odnosi; bez njega ne bi bilo fotografije" (Barthes, 1981: 76).

Šejla Kamerić kroz fotografiju vlastitoga lika jednoj takvoj stvarnosti suprotstavlja sasvim drugačiju. Pitamo se: „Je li djevojka s fotografije ona kojoj je upućen zapisani trag u vremenu i prostoru srebreničke tragedije?" Upravo u davanju odgovora krije se snažni učinak predočene monokromatske kompozicije. Fotografijom dominira figura djevojke. Fotografirana na bijeloj pozadini, obučena u bijelu majicu, Kamerić zauzima položaj sudionika/aktera u izravnoj komunikaciji s izmišljenim sugovornikom. Predimenzioniran u odnosu na kompoziciju te pozicioniran u prvi plan, grafit postaje najvažnija informacija. Autorica suočava vlastiti lik s grafitom, nastoji uspostaviti dijalog s njim, ali promatrač je svjedok neostvarene komunikacije.

Značenje vizuala oblikuje se suočavanjem dvaju suprotstavljenih značenja. Prvo je artikulirano namjerom autorice da se poistovjeti s djevojkom koja "smrdi na govno, koja nema zube i ima brkove“. Na taj način priziva se izmišljeni lik grafitom opisane djevojke, žene koja je preživjela strahote genocida, ali i svake druge koja nije mogla izbjeći djelovanje traumatičnoga povijesnog događaja kakav je rat. Značenje grafitnoga ispisa poništeno je vrijednostima koje nosi fotografija autorice Kamerić. Ona svojim stavom sugerira jaku i snažnu ženu, sposobnu provocirati i kritizirati trivijalni sud nizozemskoga vojnika. Izlaganje vlastitoga tijela pogledu i promatranju kao i usmjereni pogled prema promatraču čitamo kao znak preziranja sramnoga i nedopuštena ispisa te neodgovorna ponašanja kako međunarodne zajednice, uN-a tako i drugih međunarodnih organizacija koje su bile zadužene za zaštitu srebreničke enklave.

Rad Šejle Kamerić u svome složenom iskazu funkcionira na više razina: svjedočanstvo stvarnoga iskaza nizozemskoga vojnika, traumatično iskustvo srebreničke djevojke s kojom se autorica identificira kao i iskustvo umjetnice u bosanskohercegovačkome poslijeratnom društvu. Kroz procese performativnoga, demonstrativnoga i reprezentacijskoga 
djelovanja predočeni rad utjelovljuje elemente preživljavanja, prevođenja i sjećanja (usp. Wagner-Pacifici, 2005: 303). Njegov vizualni i značenjski potencijal postaje svjedokom traumatičnoga djelovanja drugoga reda.

\section{1945-1995-2015 (2015) Tarik Samarah}

Tarik Samarah, poznati bosanskohercegovački fotograf i osnivač $G a-$ lerije 11/07/95, autor je niza fotografija koje trajnom postavkom u galeriji pružaju uvid u srebreničku traumu. Svaka od tih fotografija, kao i rad kojim je Samarah 2015. godine najavio projekt pod nazivom 1945-19952015, problematizira traumatično iskustvo i njegov utjecaj. Cilj projekta bio je podsjetiti javnost širom Europe i svijeta na dvije godišnjice koje su se obilježavale te godine - dvadeseta godišnjica genocida u Srebrenici i sedamdeseta godišnjica holokausta. Autor svoj rad predstavlja na više od dvadeset javnih lokacija u vidu jumbo plakata. Ključan je njegov odabir urbanoga, a ne galerijskoga prostora kako bi rad bio dostupan široj javnosti, ne bi li što više slučajnih prolaznika pozvao na promišljanje i skrenuo pažnju na strahote genocida koje se ne smiju zaboraviti i ponoviti (usp. galerija110795.ba, 2015).

Samarahov rad suočava dvije stvarnosti projicirane u trećoj ili u vremenu kada nastaje fotografija (Slika 2.). Desnom stranom kompozicije dominira figura ženske osobe koja promatra plakat s dvjema djevojčicama. Njihova lica nisu vidljiva, naprotiv, sva tri lika okrenuta su leđima. Tekstualni ispisi uočljivi na plakatu, ali i na samoj fotografiji, informiraju nas o mjestu njezina nastanka i identitetu njezinih aktera. Srebrenička majka stoji ispred kuće Anne Frank u Amsterdamu za vrijeme trajanja izložbe Anne Frank en Familie. Naziv izložbe upućuje na to da figure djevojčica pripadaju Anni Frank i njezinoj sestri. Pogled usmjeren prema horizontu, njihova odjeća i obrisi pejzaža koji se naziru sugeriraju fotografski zapis bezbrižna ljetnog obiteljskog dana. 


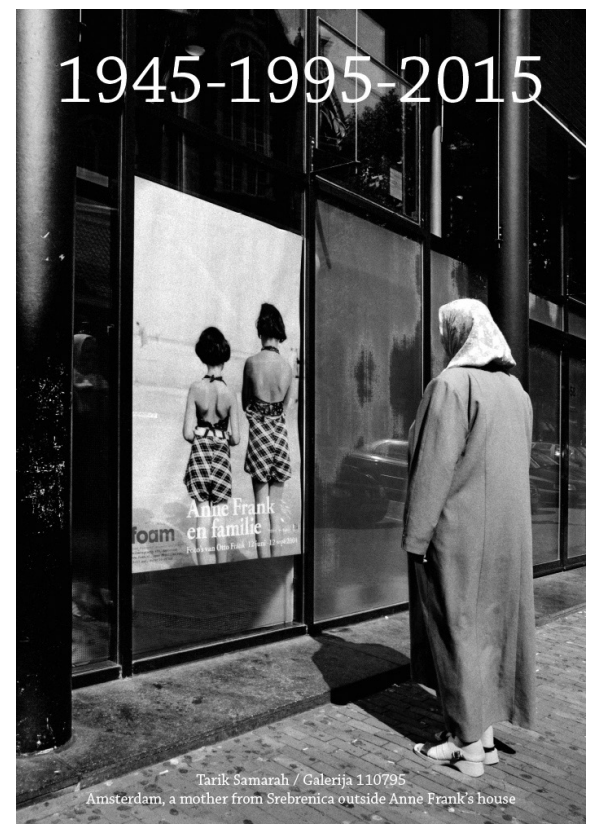

Slika 2. Tarik Samarah - 1945-1995-2015 (2015) (Ljubaznošću umjetnika)

Okamenjeni položaj tijela srebreničke majke simbolizira neizrecivost bolne prošlosti i posljedica traumatičnoga iskustva. Odsustvo aktivnosti te skrivenost njezina lika konotiraju odsustvo srebreničke majke u sadašnjosti i njezino prisustvo u odrazu plakatom ispisane prošlosti. Pažljivijim promatranjem Samarahove fotografije uočava se reflektirani lik dominirajuće ženske figure na lijevoj strani kompozicije. Ovaj put srebrenička majka izravno komunicira s djevojčicama. Njihovu sudbinu poistovjećuje s vlastitom. Obrisi njezina lica u staklenoj površini sugeriraju prisutnost života ili ga tek naznačavaju. Njezin stvarni i reflektirani lik teže započeti komunikaciju. Srebrenička majka kroz vlastitu patnju svjedoči patnjama drugih. Njezin život u sadašnjosti odvija se kroz neposredno iskustvo traumatične prošlosti. Takvoj interpretaciji pridonosi i monokromatski tretman fotografskoga zapisa. Iako fotografija bilježi stvarni trenutak sunčanoga amsterdamskog jutra, monokromatski tretman ukazuje na izostanak živoga. 
Posredstvom vlastitoga tijela i odraza lika majka ostvaruje niz dijaloga s plakatom koji promatra. Njihove putanje i značenja međusobno se susreću, prožimaju i podudaraju. Posljednji dijalog koji Samarah provocira svojim radom, s namjerom suočavanja traumatičnih prošlosti koje pripadaju različitim kontekstima i razdobljima, zbiva se u sadašnjosti $\mathrm{u}$ iskustvu recipijenta. Autor poziva recipijenta da svjedoči strahotama prošlosti s ciljem podizanja svijesti o zločinima koji se ne smiju ponoviti u budućnosti.

\section{Zaključna razmatranja}

Procesi stvaranja značenja i sjećanja na bližu ili davnu prošlost vitalni su u uspostavi i oblikovanju kolektivne svijesti i kolektivnoga identiteta. Takvi procesi oslanjaju se na različite oblike i mehanizme prijenosa sjećanja, mnemoničke prakse, koji posjeduju snagu evociranja i održavanja kontinuiteta s prošlim vremenom, te svojom formom stvaraju individualne i skupne nesvjesne procese sjećanja (usp. Rowlands, 1993: 144). Značenje prošlosti „proizilazi i opstaje zahvaljujući dinamičnoj interakciji između sadržaja historijskih događaja i oblika kolektivne memorije dostupne onima kojima je cilj očuvanje i javni ispis prošlosti“ (Wagner - Pacifici, 1996, prema Tota, 2005: 273). Takvi su objekti kulturno i materijalno uvjetovani.

Predstavljene radove Šejle Kamerić i Tarika Samaraha, u skladu s analizom i prethodnim argumentima, možemo okarakterizirati kao ključne narativne mehanizme u kulturnoj organizaciji sjećanja na traumatični događaj rata koji je označio bosanskohercegovačku suvremenu povijest i društvo. Iako već godinama djeluju kao posrednici traumatičnoga diskursa, njihova aktualnost u današnjem vremenu i društvenome kontekstu ne gubi na snazi jer svojim narativnim potencijalom rekonstruiraju prošlost i problematiziraju trenutačna društvena stanja. Vizualnim i značenjskim kodom nositelji su ideja destrukcije, razjedinjenosti i gubitka - značenja koja karakteriziraju bosanskohercegovačku stvarnost i identitet. $U$ tome činu sadržana je njihova istinska vrijednost koja će se održati do trenutka kada taj kontinuitet bude prekinut, zapravo, 
kada, riječima Michaela Rowlandsa (1993: 147), „postanu sami po sebi predmetima sjećanja“. Slijedeći koncept autorice Marianne Hirsch, radove bosanskohercegovačkih autora možemo promatrati i kroz vizuru koncepta postsjećanja. Ostvarujući različita značenja u specifičnim kontekstima, radovi postaju nositelji „inter i trangeneracijskog prijenosa traumatičnog znanja i iskustva" (2008 :106). Oni posreduju sjećanje vremenski i kvalitativno različito od sjećanja generacija koje su izravno oblikovane traumatičnim iskustvom. Povezanost s objektom odnosno iskustvom ostvaruje se kroz prikaz, projekciju i čin stvaranja, i na taj način omogućava novim generacijama stvoriti vlastito sjećanje na traumatični događaj. U tome smislu govorimo o procesu prepoznavanja, artikuliranja i prijenosa traumatičnoga iskustva kroz generacije: „Zbog vremenske udaljenosti i promjene društvenih okolnosti tokom vremena, svaka naredna generacija reinterpretira i uspostavlja sjećanje spram traumatskog događaja na svoj način i prema svojim potrebama. Taj proces obnove je, međutim, određen raspoloživim resursima te ograničenjima koja historija nameće sjećanju“ (Eyerman, 2001: 15).

Neizbježne posljedice i utjecaji prošlosti u sadašnjem vremenu ogledaju se u oblikovanju nepromjenjive predstave i identiteta jednoga kolektiva koji uspostavlja i dijeli dana sjećanja. Takve posljedice promatraju se u odnosu na prostore iz kojih dolazimo i prema kojima se krećemo (usp. Zehfuss, 2008: 64). Zajedničko sjećanje, posredovano narativima koji su promjenjivi, filtrirani kroz kulturne artefakte i druge materijalizacije, neupitno utječe na konkretizaciju kolektivnoga identiteta (usp. Assmann, 1995: 130). Ovakav potencijal pronalazimo u radovima Šejle Kamerić i Tarika Samaraha, koji kao nositelji kulturne dimenzije sjećanja na genocid in/direktno oblikuju svijest o izmijenjenome i djelomičnome poslijeratnom kolektivnom identitetu.

Dejtonskim mirovnim sporazumom (1995.), kojim je načinjen teritorijalno-politički ustroj države, srebrenička enklava istrgnuta je iz jedinstvenoga prostora Bosne i Hercegovine i pripojena entitetu Republike Srpske. Raslojenost državnoga prostora utjelovljuje razjedinjenost bosanskohercegovačkoga naroda i identiteta. Takva narativna dimenzija prepoznaje se $\mathrm{u}$ analiziranim autorskim radovima posebno kroz prikaz 
ženskoga lika/modela. Model koji označava autoricu Kamerić ili djevojku kojoj je namijenjen grafit nizozemskoga vojnika te likovi djevojčica i srebreničke majke u radu Tarika Samaraha simbolični su prikazi gubitka prostorne i obiteljske pripadnosti i jedinstva. Pitanja su: „Hoće li narodi i prostori Bosne i Hercegovine jednoga dana opet biti jedinstveni?", „Hoće li srebrenička majka doživjeti da žrtve budu identificirane i ukopane?" $i$ „Hoće li presude za ratne zločine biti pravedne?" Takva pitanja posredstvom vlastitih umjetničkih promišljanja postavljaju Šejla Kamerić i Tarik Samarah. Njihovi radovi, nositelji kulturne dimenzije sjećanja na genocid i značenja traumatskoga iskustva, snažnim vizualnim i narativnim sredstvima problematiziraju danu prošlost iz sadašnjega i budućega oblikovnog koda bosanskohercegovačkoga identiteta.

\section{Literatura}

- Assmann, JAN (1995) "Collective Memory and Cultural Identity“, Czaplicka, John (prev.) New German Critique, br. 65., str. 125 133.

- Barthes, Roland (1981) Camera Lucida: Reflections on Photography, Hill and Wang, New York.

- Brockmeier, Jens - Harré, Rom (2001) „Narrative: Problems and promises of an alternative paradigm", BROCKMEIER, JENS Carbaugh, Donal (ur.) Narrative and identity: Studies in autobiography, self, and culture, John Benjamins Publishing Company, Amsterdam -Philadelphia, str. 39 - 58.

- Brockmeier, Jens (2002) „Introduction: Searching for Cultural Memory“, Culture EPsychology, god.viII, br. 1, str. 5 - 14.

- Brockmeier, Jens (2010) „After the Archive: Remapping Memory“, Culture E Psychology, god. Xvi, br. 1, str. 5- 35.

- David, Emmanuel (2008) "Cultural Trauma, Memory, and Gendered Collective Action: The Case of Women of the Storm Following Hurricane Katrina", NWSA Journal, god. xx, br. 3, str. $138-162$. 
- Eyerman, Ron (2001) Cultural Trauma: Slavery and the Formation of African American Identity, Cambridge University Press, Cambridge.

- Ha£as, Elżbieta (2010) „Time and Memory: A Cultural Perspective", Trames, god. XIV, br. 4, str. $307-322$.

- Halbwachs, Maurice (1980) The Collective Memory, Harper \& Row, New York.

- Hale, Grace Elizabeth (1998) Making Whiteness: the culture of segregation in the South, 1890-1940, Vintage Books, New York.

- Hirsch, Marianne (2008) "The Generation of Postmemory“, Poetics Today, god. XxIx, br. 1, str. $103-128$.

- „Obavijest o projektu '1945-1995-2015' u sklopu ICOM News” (o6. 10. 2015.) GALERIJA 11/o7/95 <http://galerija110795.ba/bs/obavijest-o-projektu-1945-1995-2005-u-sklopu-icom-news/>, (23. V. 2019.).

- Rowlands, Michael (1993) "The Role of Memory in the Transmission of Culture", World Archaeology, god. xxv, br. 2, str. 141 $-151$.

- Schwartz, Barry i dr. (2005) "Collective Memory: Why Culture Matters“, Jacobs, Mark D. - Weiss Hanrahan, Nancy (ur.) The Blackwell Companion to the Sociology of Culture, Blackwell, Oxford, str. $253-271$.

- Tota, Anna Lisa (2005) „Counter-Memories of Terrorism: The Public Inscription of a Dramatic Past“, JACOBS, Mark D. - WeIsS Hanrahan, Nancy (ur.) The Blackwell Companion to the Sociology of Culture, Blackwell, Oxford, str. $272-284$.

- Wagner - Pacifici, Robin (2005) „Dilemmas of the Witness", Jacobs, Mark D. - Weiss Hanrahan, Nancy (ur.) The Blackwell Companion to the Sociology of Culture, Blackwell, Oxford, str. $302-314$.

- Zenfuss, Maja (2007) Wounds of Memory: The Politics of War in Germany, Cambridge University Press, Cambridge. 
Amila HandžIĆ Ferović

\section{CULTURAL DIMENSION OF REMEMBERING GENOCIDE IN SREBRENICA}

\section{Abstract}

The fundamental idea behind this paper is the interpretation of genocide in Srebrenica using the term and meaning of "cultural trauma". The research is based on the analysis and challenging of the visual and semantic dimensions of the work entitled Bosnian Girl by Šejla Kamerić, an artist from Bosnia and Herzegovina, as well as the 1945-1995-2005 billboards by photographer Tarik Samarah. These works, originated in the post-war period, are acknowledged as the key cultural mechanisms of interpretation and understanding of the Srebrenica traumatic events. The expressions of a changed and fragmented collectivity are reflected in the framework of the past semantically shaped by different visual means and their interrelationships. The author observes the powerful symbolic potential of these works as a space for archiving knowledge and cultural dimension of remembering the genocide in Srebrenica and integrating the historical content in the framework of the contemporary and future Bosnian and Herzegovinian social context. The narratives of cultural memory, the works of artist Kamerić and photographer Samarah examine the effects of the past on the processes of re/construction of the collective identity.

Keywords: genocide; cultural trauma; cultural memory; narrative discourse; collective identity 